\title{
Is the Pectoralis Myocutaneous Flap in Intraoral and Oropharyngeal Reconstruction Outdated?
}

\author{
Cees B. IJsselstein, MD, Steven E.R. Hovius, MD, PhD, Bas L.E.F. ten Have, MD, \\ Siegwart J.M. Wijthoff, MD, Gijsbert J. Sonneveld, MD, Cees A. Meeuwis, MD, PhD, \\ Paul P.M. Knegt, MD, PhD, Rotterdam, The Netherlands
}

\begin{abstract}
METHODS: Our experience with 224 immediate pectoralis major myocutaneous flap reconstructions in patients with carcinomas of the oral and oropharyngeal cavities is presented.
\end{abstract}

RESULTS: Although flap-related complications developed in $53 \%$ of the patients, all flaps survived, and we had no major skin paddle loss. The incidence of reoperation due to flap-related complications was $2 \%$. All other complications were minor and did not affect the length of hospitalization. Analysis showed no significant risk factors for the development of complications. Because of fistula formation, infection, or metal exposure, plate removal was necessary in $10 \%$ of the $A O$ fixation plates used in cases of mandibular swing. This occurred in $68 \%$ of the anterior and $22 \%$ of the lateral mandibular reconstructions performed with a reconstruction plate $(P<0.05)$. CONCLUSIONS: We conclude that a reconstruction plate is unsatisfactory for anterior mandibular continuity reconstruction and debatable for lateral mandibular reconstruction. At present, anterior defects are reconstructed with free vascularized osteocutaneous flaps that should probably also be used for lateral mandibular reconstruction. Furthermore, in a large number of series, it is reported that free flaps also have high complication rates and $5-10 \%$ flap loss. As all pectoralis major flaps survived in our series, it still remains a good choice in intraoral and oropharyngeal reconstruction when there is no necessity to reconstruct bone. Am J Surg. 1996;172:259-262.

$\mathrm{T}$ he pectoralis major myocutaneous flap, described by Ariyan $^{1,2}$ in 1979 , has always been a mainstay in the immediate reconstruction of defects of the oral and oropharyngeal cavities. ${ }^{1-10}$ Its abundant tissue, with an excellent axial vascularization by the thoracoacromial artery, and its anatomic proximity and reliability, facilitate the im-

From the Department of Plastic and Reconstructive Surgery (CBI, SERH, BLEFtH, GJS), and the Department of Head and Neck Surgery (PPMK), University Hospital, Rotterdam Dijkzigt; and the Department of Plastic and Reconstructive Surgery (SJMW), and the Department of Head and Neck Surgery (CAM), Dr. Daniel Den Hoed Cancer Center, Rotterdam, The Netherlands.

Requests for reprints should be addressed to C.B. IJsselstein, MD, Department of Surgery, Zuiderziekenhuis, Groene Hilledijk 315,3075 EA Rotterdam, The Netherlands.

Manuscript submitted June 7, 1995 and accepted in revised form December 15, 1995. mediate reconstruction of a variety of defects in the head and neck area. This technique also has a low donor-site morbidity and esthetic benefits: no split skin grafts are needed to cover the donor area and the muscular pedicle of the flap replaces the ipsilateral sternocleidomastoid muscle in cases of neck dissection, thus restoring symmetry of the neck. Moreover, the muscular pedicle provides an excellent and safe cover for the carorid artery, especially in relation to postopcrative radiotherapy.

At the Academic Hospital, Rotterdam, Dijkzigt, and the Dr. Daniel Den Hoed Cancer Center, head and neck surgeons and plastic surgeons are involved in a team approach in the resection and reconstruction of patients with carcinomas of the head and neck. In view of the large number of recently published accounts of free vascularized flaps in head and neck reconstruction following intraoral and oropharyngeal tumor resection, we present a review of our experience with 224 pectoralis major myocutaneous flaps in 224 patients with carcinomas of the oral cavity and oropharynx.

The purpose of this study is to analyse the complications of this reconstuction technicue, as well as to indicate in which patient group a free vascularized flap should have been used. Our results will be compared, as far as possible, with large international series in which the pectoralis major flap, as well as the free vascularized flap, has been used.

\section{MATERIALS AND METHODS}

From 1979 to 1992, at the Academic Hospital Rotterdam, Dijkzigt, and the Dr. Daniel Den Hoed Cancer Center, a total of 224 patients with intraoral or oropharyngeal cancer had an immediate reconstruction of their defects with 224 pectoralis major myocutaneous flaps. Data were obtained from a review of the hospital charts.

There were 146 men and 78 women aged $28-84$ years, with a mean age of 59 years. Histology included 224 $(100 \%)$ patients with squamous cell carcinoma. One hundred and ninety-one $(85 \%)$ patients had a history of significant tobacco use, and $189(84 \%)$ patients were heavy drinkers. Only $13(6 \%)$ patients were both nonsmokers and nondrinkers. Table I shows that $134(60 \%)$ patients did not have any previous treatment. On $46(21 \%)$ occasions, surgical resection and reconstruction followed planned radiotherapy (surgery being performed 4-6 weeks following radiotherapy). On 19 (8\%) occasions, surgery was salvage surgery, following failed radiotherapy. In all cases, a neck dissection was performed.

All the pectoralis major myocutaneous flap reconstructions were performed with a standard technique (Figure) ${ }^{3}$ 
TABLE I

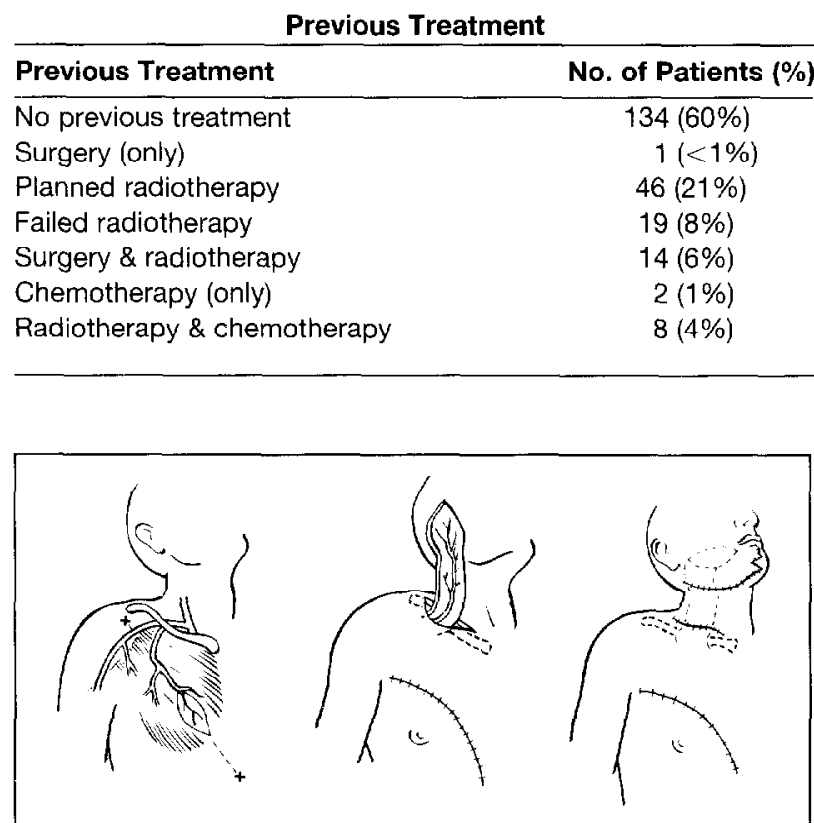

Figure. Pectoralis major myocutaneous flap operative technique.

Eighty-nine percent of the reconstructions were performed by the same surgeon.

\section{RESULTS}

In our series, 119 patients experienced 129 flap-related complications, an overall rate of $53 \%$. Table II shows these complications. No total flap loss occurred. Twenty-nine (13\%) patients had partial skin paddle loss. Retrospectively, it was difficult to determine the extent of skin paddle loss exactly, but no muscle loss developed and no reoperations were necessary. Twelve $(5 \%)$ patients developed a wound infection. Minor orocutaneous fistulas were found in $46(21 \%)$ patients, all of which closed spontaneously. In $2(1 \%)$ cases, major fistulas developed that needed secondary repair. One of these patients, who received postoperative radiotherapy, required a second pectoralis major myocutaneous flap to achieve healing of the fistula. The other patient developed an orocutaneous fistula secondary to separation of the suture line at the anterior floor of the mouth. This patient required a secondary procedure in which a local resection was followed by primary closure. Wound dehiscence occurred in $37(17 \%)$ patients. All healed without a secondary procedure. Three $(1 \%)$ patients had a postoperative bleeding that required re-exploration. One of these patients had oral anticoagulative medication because of cardiac disease.

No significant differences in the incidence of complications were found in regard to gender and alcohol/tobacco use. Previous radiothcrapy, tumor stagc, and location of tumor also had no affect on complication rates. None of the above-mentioned flap-related complications, except major fistulas, affected the hospital stay (mean stay 25 days). In 5 cases a (minor) fistula and in 1 case a wound dehiscence developed secondary to early local tumor recurrence.

In 140 cases of mandibular swing (63\% of total), osteosynthesis of the mandible was performed using an $\mathrm{AO}$ fixation plate. In $14(10 \%)$ of these patients, the fixation plate
TABLE ॥

Flap-Related Complications

\begin{tabular}{lc}
\hline Flap-Related Complications & No. of Patients $(\%)$ \\
\hline Total necrosis & 0 \\
Partial necrosis (skin paddle) & $29(13 \%)$ \\
Major fistula & $2(1 \%)$ \\
Minor fistula & $46(21 \%)$ \\
Infection & $12(5 \%)$ \\
Wound dehiscence & $37(17 \%)$ \\
Bleøding & $3(1 \%)$
\end{tabular}

had to be removed because of complications such as fistula formation, infection, or metal exposure.

In $15(6.7 \%$ of the total cases $)$ patients, either a pullthrough resection, without mandibulotomy, or a mandibular resection, without continuity reconstruction, was performed.

In $69(31 \%)$ patients, an $\mathrm{AO}$ reconstruction plate was used to restore mandibular continuity. In 19 of $28(68 \%)$ cases of anterior mandibular reconstructions, it was necessary to remove the plate, due to fistula formation, infection, or metal exposure. This occurred in 9 of $41(22 \%)$ cases of lateral mandibular reconstruction $(P<0.05$; chi-square analysis).

\section{DISCUSSION}

The pectoralis major myocutaneous flap was, until recently, the flap of choice for many head and neck surgeons. Its excellent axial vascularization, the ease of execution, the anatomic proximity, and the low donor site morbidity all facilitate the immediate reconstruction of a variety of defects in the head and neck ared. In cases of unilateral neck dissection, the muscular pedicle restores symmetry of the neck and provides a safe cover for the carotid artery. A carotid blow-out can occur in head and neck oncology patients if the carotid artery is not well covered in an irradiated area. In our series, no carotid blow-out was encountered in flap-covered carotid arteries. The disadvantages of the pectoralis major myocutaneous flap are the bulkiness of the flap (skin-subcutaneous paddle in women, the bulk of the muscle in the neck, especially in bilateral neck dissections), the possible development of breast deformity, and, occasionally, the transfer of hair-bearing skin, depending on the acceptor location. But these disadvantages are outweighed by the advantages, and neither in earlier studies ${ }^{5}$ nor in our own study were these disadvantages experienced as serious problems.

The incidence of complications in a large number of previously reported studies of pectoralis major flaps differs considerably, but it is frequently high (Table III). In our series, the total incidence of complications was considerable. It must be remembered however that, like Kroll et $\mathrm{al}^{6}$ and Shah et $\mathrm{al}^{4}{ }^{4}$ we included all those cases of minor flap loss, wound dehiscence, minor fistula formation, and wound infection, which were not reported consistently in other series. In our series, all flaps survived, and we encountered only partial skin paddle loss, without muscle loss. In comparison to earlier studies, our incidence of reoperation due to flap-related complications was low $(2 \%)$. Of the patients who required secondary procedures, 2 had major orocutaneous fistulas and 3 had a postoperative bleeding. 


\begin{tabular}{|c|c|c|c|c|c|c|c|}
\hline \multicolumn{8}{|c|}{ Literature } \\
\hline Author & $\begin{array}{l}\text { Number } \\
\text { Flaps }\end{array}$ & $\begin{array}{c}\text { Total } \\
\text { Necrosis } \\
(\%)\end{array}$ & $\begin{array}{c}\text { Partial } \\
\text { Necrosis } \\
(\%)\end{array}$ & $\begin{array}{c}\text { Wound } \\
\text { Dehiscence } \\
(\%)\end{array}$ & $\begin{array}{c}\text { Fistula } \\
(\%)\end{array}$ & $\begin{array}{c}\text { Total } \\
\text { Complications } \\
(\%)\end{array}$ & $\begin{array}{c}\text { Reoperations } \\
(\%)\end{array}$ \\
\hline Baek et $\mathrm{al}^{3}(1982)$ & 133 & 1.5 & 7 & 13 & 13.5 & 40 & 8 \\
\hline Mehrhof et $\mathrm{al}^{7}$ (1983) & 73 & 4 & 12 & 12 & 16 & 54 & 36 \\
\hline Ossoff et al ${ }^{10}(1983)$ & 95 & 1 & 4 & 10 & 5 & 35 & $?$ \\
\hline Wilson et al ${ }^{9}(1984)$ & 112 & 7 & 9 & $?$ & $?$ & 16 & 2 \\
\hline Kroll et al ${ }^{6}(1990)$ & 168 & 2.4 & 17 & 26 & 21 & 63 & $?$ \\
\hline Shah et $\mathrm{al}^{4}(1990)$ & 211 & 3 & 29 & 26 & 29 & 63 & 26 \\
\hline Ysselstein et al (1995) & 224 & 0 & 13 & 17 & 21 & 53 & 2 \\
\hline
\end{tabular}

The goal of immediate reconstruction is wound closure, using a one-stage procedure. Therefore, any flap-related complications that necessitate a second operation should be viewed as a failure. Complications that did not require a surgical revision were all minor and did not affect the length of hospitalization (mean stay 25 days). Patients with head and neck cancer are frequently malnourished, often use tobacco, and generally are not ideal surgical candidates. The defects are frequently large and exposed to saliva, bacterial contamination, and other unfavorable factors. So the occurrence of complications such as wound dehiscence, flap-edge necrosis, and fistula formation is not unique to the pectoralis major flap and must he expected to some extent with any currently available method of reconstruction. Moreover, in many cases it is difficult to determine whether a complication (like wound dehiscence) should be classified as an acceptor-site complication or as a flap-related complication.

Shah et $\mathrm{al}^{4}$ reported the following risk factors to be significant for the development of flap complications using the pectoralis major flap: age over 70, female gender, nomographic overweight, albumin less than $4 \mathrm{~g} / \mathrm{dL}$, use of the flap in reconstruction of the oral cavity after major glossectomy, and the presence of other systemic diseases. In our study, no significant differences in the incidence of complications were found in regard to gender and alcohol/tobacco use. Previous radiotherapy, tumor stage, and tumor location also had no effect on complication rates. These findings are similar to the findings in earlier studies, ${ }^{3,6,11,12}$

During surgery for cancer of the oral cavity or oropharynx, the mandible is often osteotomized or partly resected. Frequently, osteosynthesis plates or, in appropriate cases, reconstruction plates are used. In their study in 1991, Schusterman et al ${ }^{13}$ demonstrated that the $\mathrm{AO}$ reconstruction plate is inadequate in most cases of anterior mandibular reconstruction, no matter how well a thick, vascularized flap might be wrapped around the reconstruction plate. They reported $67 \%$ plate extrusion in anterior mandibular reconstruction and $7 \%$ plate extrusion in lateral reconstruction. ${ }^{13}$ Mehrhof et al ${ }^{7}$ described $80 \%$ reconstruction plate removal due to fistula formation or metal exposure in cases of mandibular continuity reconstruction. They did not differentiate between anterior and lateral mandibular reconstructions. In our series, it was necessary to remove the plate in $68 \%$ of the anterior mandibular continuity reconstructions performed with an $\mathrm{AO}$ reconstruction plate because of fis- tula formation, infection, or metal exposure. This occurred in $22 \%$ of the lateral mandibular reconstructions with an $\mathrm{AO}$ reconstruction plate (statistically significant difference, $P<0.05$ ).

Due to the high incidence of complications associated with the use of a plate combined with a pectoralis major flap for anterior mandibular reconstruction, we stopped using reconstruction plates for anterior mandibular reconstructions in 1987. Since then, we have been reconstructing all anterior mandibular defects with a free vascularized ostcocutaneous flap. Most lateral mandibular defects are still reconstructed with an $\mathrm{AO}$ reconstruction plate. But in view of the incidence of $22 \%$ complications, this is open to discussion. Although the difference in the incidence of complications between lateral reconstruction plates $(22 \%)$ and fixation plates used in cases of mandibulotomy for mandibular swing $(10 \%)$ is considerable, no statistically significant difference exists.

In recent studies, ${ }^{14-17}$ the free vascularized flap has been advocated as the first choice for reconstruction of hcad and neck cancer defects. However, Schusterman et al ${ }^{15}$ reported an overall complication rate of $36.1 \%$ and a flap loss rate of $5.5 \%$ in their large series of 308 free flaps for repair of head and neck cancer defects. Soutar et al ${ }^{16}$ reported $10 \%$ total flap loss in their series of 60 free radial forearm flaps. Vaughan ${ }^{18}$ reported $7.5 \%$ flap failures. And in their series of 200 free inferior rectus abdominis tlaps for head and neck reconstruction, Nakatsuka et $\mathrm{al}^{17}$ reported $10(5 \%)$ cases of total flap necrosis, 5 cases of major fistulas, and 1 case of hernia that required surgical repair, resulting in a reoperation rate of $8 \%$.

Based on our experience and the fact that the reported flap loss and complication rates of free vascularized flaps are far from low, we conclude that the pectoralis major flap technique is still a reliable one for one-stage intraoral or oropharyngeal reconstruction, and it remains a very good choice, except in cases of mandibular continuity reconstruction. The pectoralis flap technique requires less operating time than the free flap one, and the muscular pedicle offers a safe cover for the carotid artcry. However, it has a limited arc of rotation. Positioning of a free flap is unhampered by limitations of arc of rotation, but the technique requires microsurgical training and it does not protect the carotid artery in cases of neck dissection. Although the incidence of complications in our series, as well as in other large series of pectoralis major flaps, was far from low, most complications were minor, and the actual incidence of flaps failing to accomplish 
their intended purposes and requiring secondary repair was, in fact, minimal.

\section{REFERENCES}

1. Ariyan $\mathrm{S}$. The pectoralis major myocutaneous flap. A versatile flap for reconstruction in the head and neck. Plast Reconst Surg. $1979 ; 63: 73-81$.

2. Ariyan $\mathrm{S}$. Further experience with the pectoralis major myocutaneous flap for immediate repair of defects from excision of head and neck cancers. Plast Reconst Surg. 1979;64:605-612.

3. Baek SM, Lawson W, Biller HF. An analysis of 133 pectoralis major myocutaneous flaps. Plast Reconst Surg. 1982;69:460-467.

4. Shah JP, Haribhakti V, Lorce TR, Sutaria P. Complications of the pectoralis major myocutaneous flap in head and neck reconstruction. Am J Surg. 1990;160:352-355.

5. Biller HF, Baek SM, Lawson W, et al. Pectoralis major myocutaneous island flap in head and neck surgery. Analysis of complications in 42 cases. Arch Otolaryngol. 1981;107:23-26.

6. Kroll SS, Goepfert H, Jones M, et al. Analysis of complications in 168 pectoralis major myocutaneous flaps used for head and neck reconstruction. Ann Plast Surg. 1990;25:93-97.

7. Mehrhof AI, Rosenstock A, Neifeld JP, et al. The pectoralis major myocutaneous flap in head and neck reconstruction. Anlalysis of complications. Am J Surg. 1983;146:478-482.

8. Schuller DE. Pectoralis myocutaneous flap in head and neck reconstruction. Arch Otolaryngol. 1983;109:185-189.

9. Wilson JSP, Yiacoumettis AM, O'Neill T. Some observations on 112 pectoralis major myocutaneous flaps. Am J Surg. 1984;147:273279.
10. Ossoff RH, Wurster CF, Berktold RE, et al. Complications after pectoralis major myocutaneous flap reconstruction of head and neck defects. Arch Otolaryngol. 1983;109:812-814.

11. Marcial VA, Gelber R, Kramer $S$, et al. Does preoperative irradiation increase the rate of surgical complications in carcinoma of the head and neck? Cancer. 1982;49:1297-1301.

12.Keidan RD, Kusiak JF. Complications following reconstruction with the pectoralis major myocutaneous flap; the effect of prior radiation therapy. Laryngoscope. 1992;102:521-524.

13. Schusterman MA, Reece GP, Kroll SS, Weldon ME. Use of the AO plate for immediate mandibular reconstruction in cancer patients. Plast Reconst Surg. 1991;88:588-593.

14. Kroll SS, Reece GP, Miller MJ, Schusterman MA. Comparison of the rectus abdominis free flap with the pectoralis major myocutaneous flap for reconstructions in the head and neck. Am I Surg. 1992;164:615-617.

15. Schusterman MA, Miller MJ, Reece GP, et al. A single center's experience with 308 free flaps for repair of head and neck cancer defects. Plast Reconst Surg. 1994:93:472-480.

16. Soutar DS, McGregnr IA. The radial forearm flap in intraoral reconstruction: the experience of 60 consecutive cases. Plast Reconst Surg. 1986;78:1-8.

17. Nakatsuka ' l, Harii K, Yamada A, et al. Versatility of a free inferior rectus abdominis flap for head and neck reconstruction: analysis of 200 cases. Plast Reconst Surg. 1994;93:762-769.

18. Vaughan ED. The radial forearm free flap in orofacial reconstruction. Personal experience in 120 consecutive cases. J Craniomaxillofac Surg. 1990;18:2-7. 